\title{
A Rare Case of Pulmonary Restrictive Syndrome after Liquid Silicone Injection: The Role of the Plastic Surgeon
}

\author{
Pier Paolo Bonfirraro ${ }^{1}$ Davide Sallam ${ }^{1}$ Maurizio Verga ${ }^{1}$ Bernardo Righi ${ }^{1}$ Gabriele Mevio ${ }^{1}$ \\ Denis Codazzi ${ }^{1} \quad$ Francesco Leone $^{1}$ Marcello Carminati ${ }^{1}$
}

${ }^{1}$ Department of Plastic and Reconstructive Surgery, ASST Papa Giovanni XXIII, Bergamo, Italy
Address for correspondence Davide Sallam, MD, Piazza OMS 1. Bergamo, 24127, Italy (e-mail: davide.sallam@gmail.com).

Indian J Plast Surg:2021;54:90-93.

\begin{abstract}
Keywords

- silicone breast injection

- silicone pneumonitis

- deep inferior epigastric perforator flap

Despite being especially used in its solid form, silicone is still injected as a liquid filler for breast contouring in many countries. Here, we present a rare case of a woman with silicone pneumonitis and extended breast scarring after breast silicone injection. Because of evidence of a restrictive syndrome due to the thoracic extensive scarring tissue and the high demand of oxygen therapy, as jointly agreed with the pulmonologists, we decided to perform a surgical asportation of the scarring tissue and covering with microsurgical flap. We chose the deep inferior epigastric perforator flap mainly because of the large amount of skin that is possible to use, the good skin texture matching, and the possibility of double team working without changing patient's position.
\end{abstract}

\section{Introduction}

Silicones were studied and classified for a hypothetic industrial use by the English chemist, Frederich Stanley Kipping in $1940 .{ }^{1}$ At the beginning, they were harangued as "sticky messes" and it was believed there would be no practical uses for these materials. Since that time, many things changed and now silicone is one of the most used materials in medical industry. Despite being especially used in its solid form, it is still injected as a filler for aesthetic purposes in many countries. Here, we present a rare case of a woman with silicone pneumonitis after breast silicone injection.

\section{Case Report}

A nonsmoker 55-year-old woman was admitted in our hospital for dyspnea associated with intermittent fever up to $38^{\circ} \mathrm{C}$. These symptoms had been present for a few months during effort, then also at rest. Her medical history consisted of primary hyperparathyroidism under pharmacological therapy and no allergies. Besides she reported many breast silicone injections for aesthetic purposes $\sim 25$ years before.

The clinical examination of the thorax showed the presence of an extended breast scarring bilaterally, a complete deformity of the breast cone with nipple-areola complex herniation and a hard-full-thickness scar tissue with many subcutaneous nodules, observed through palpation of the remaining breast tissues ( - Fig. 1).

Spirometry exam showed values compatible with a pulmonary restrictive syndrome. Chest X-ray investigation did not reveal any abnormality. The subsequent computer tomography scan excluded any sign of pulmonary embolism or infectious pneumonitis but it showed an interstitial lung disease, with a reticular fibrosis pattern, and several traction bronchiectasis. No lymphadenopathies or pleural effusion was noticed. Breast tissues showed an important and dishomogeneous increase in thickness with presence of hyperdense nodules of silicone ( $\boldsymbol{- \text { Fig. }}$ 2). The ultrasound study published online

February 22, 2021
DOI https://doi.org/

$10.1055 / \mathrm{s}-0040-1721862$

ISSN 0970-0358. (c) 2021. Association of Plastic Surgeons of India.

This is an open access article published by Thieme under the terms of the Creative Commons Attribution-NonDerivative-NonCommercial-License, permitting copying and reproduction so long as the original work is given appropriate credit. Contents may not be used for commercial purposes, or adapted, remixed, transformed or built upon. (https://creativecommons.org/licenses/by-nc-nd/4.0/).

Thieme Medical and Scientific Publishers Pvt. Ltd. A-12, 2nd Floor, Sector 2, Noida-201301 UP, India 


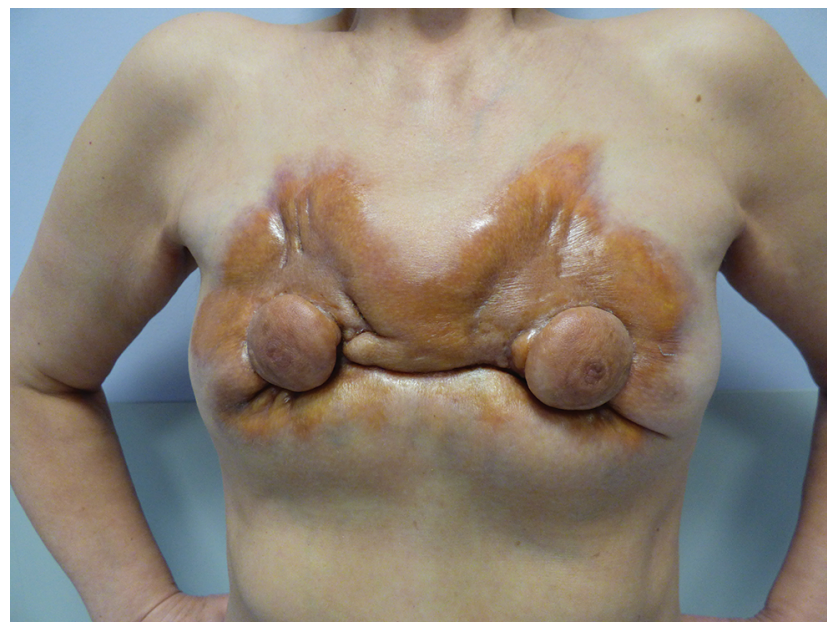

Fig. 1 Breast tissues condition with presence of an extended hard-full-thickness scar with many subcutaneous nodules bilaterally and a complete deformity of the breast cone with nipple-areola complex herniation.

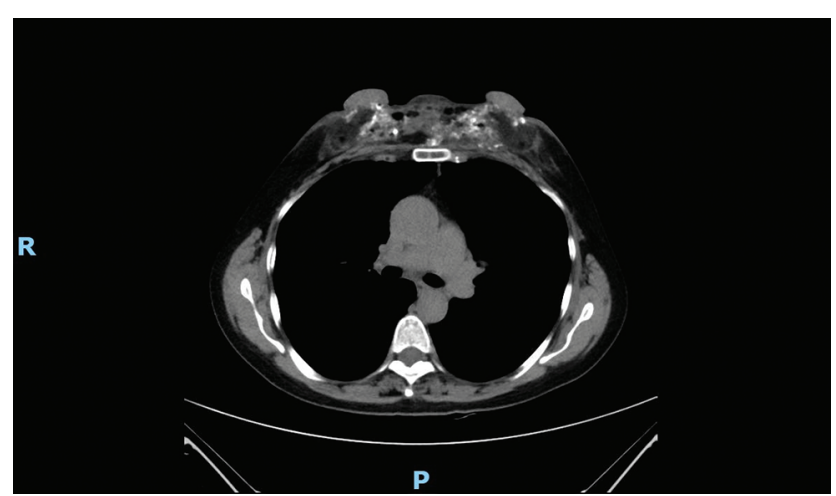

Fig. 2 Computer tomography scan showing an important and dishomogeneous increase in thickness of breast tissues with the presence of hyperdense nodules of silicone.

of axillary nodes displayed a similar bilateral pattern with lymph nodes fulfilled with foreign material. The bronchoscopy procedure with analysis of the bronchoalveolar fluid showed the presence of alveolar macrophages with intracytoplasmatic deposits of foreign particulate material, birefringent in polarized light. Subsequent immunologic tests excluded any autoimmune disease.

The patient was then treated for 10 days with oxygen therapy, beclomethasone, salbutamol, and broad-spectrum antibiotic therapy. In agreement with pulmonologists' diagnosis of a restrictive syndrome due to the thoracic extensive scarring tissue and the high demand of oxygen therapy, we planned an extensive surgical removal of the scarring tissue. We also planned a simultaneous reconstruction with a

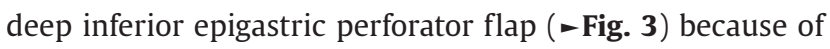
the wide bilateral involved area and the possibility of sternal exposure. The debridement was performed involving also part of the muscular plane that was broadly filled with liquid silicone ( - Fig. 4). The flap was harvested bilaterally based on a preoperative computed tomography angiography to determine the exact position of perforators (- Figs. 5A and $\mathbf{5 B}$ ). The deep inferior epigastric artery was anastomized with

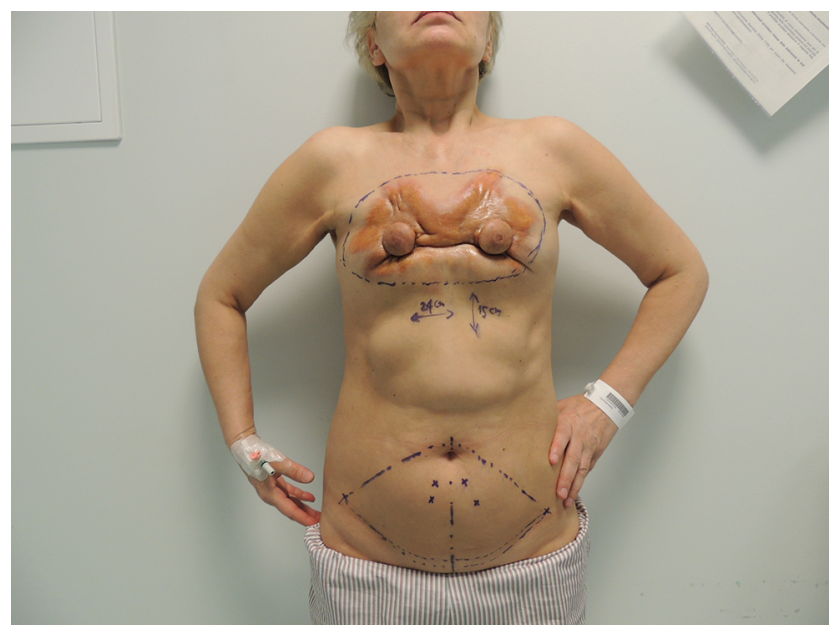

Fig. 3 Preoperative planning of scar removal and reconstruction with bilateral deep inferior epigastric perforator flap. Perforators are marked with crosses.

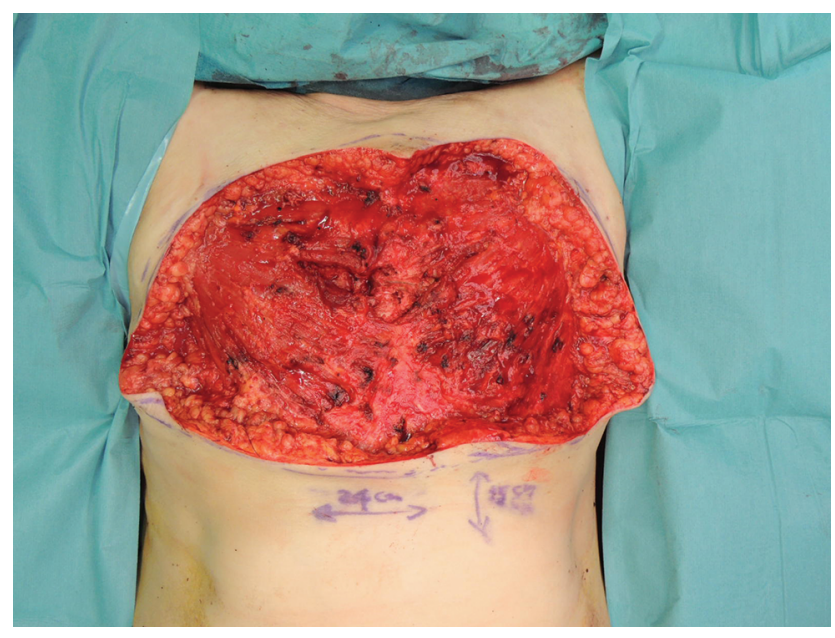

Fig. 4 The debridement was carried out involving also the muscular fascia and part of the muscular superficial plane that was broadly filled with liquid silicone.

the thoracodorsal artery, the same for the two comitantes veins. During the operation, we observed venous congestion. Therefore, we decided to perform two additional anastomoses between the superficial epigastric and the lateral thoracic veins. At the end of the procedure, four drains were positioned: two in the donor site and one for each breast. The patient was transferred in the intensive care unit department for the first 48 postoperative hours and a heater lamp was applied above the flap. The flap was monitored through handheld Doppler every hour and observing capillary refill and temperature. Low molecular weight heparin and broad-spectrum antibiotic medication (cefazolin $1 \mathrm{~g}$ thrice daily [TID]) were administered for the first 10 days. Analgesic covering was reached using paracetamol $1 \mathrm{~g}$ TID and ketoprofen $10 \mathrm{mg}$ twice daily. After 48 hours, the patient was transferred to the plastic surgery department where she was maintained at rest until the fifth postoperative day. Drains were removed completely after 8 days with a fluid output lower than $20 \mathrm{cc}$ each. The patient was discharged 

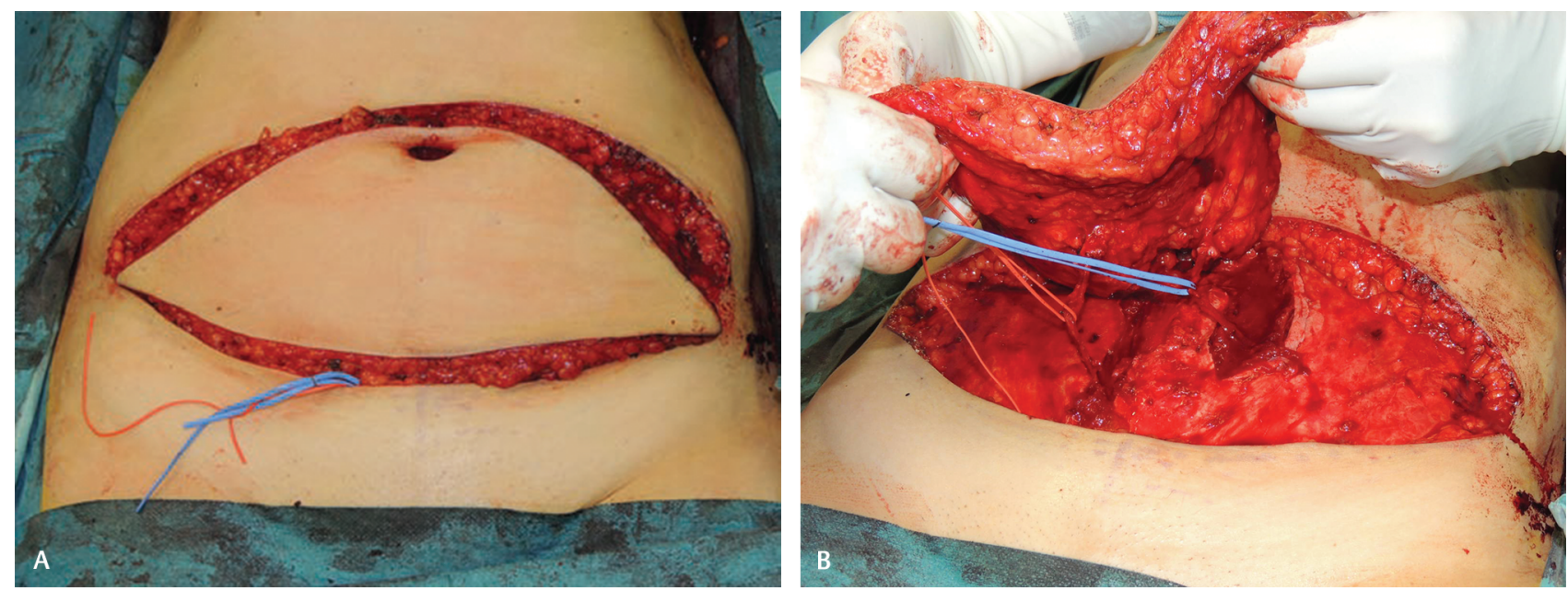

Fig. 5 Intraoperative incision (A) and perforators and nutrient vessels dissection (B).

10 days after the procedure. A compressive abdominal girdle was applied and physical activity was avoided for 6 weeks (-Fig. 6).

\section{Discussion}

The term "silicone" indicates a large family of long-chain synthetic polymers containing silicon, methyl, and oxygen atoms. The degree of polymerization and the number of cross-linked bonds determine its viscosity. It exists in solid, gel, or liquid form, which is called polydimethylsiloxane. Polydimethylsiloxanes are water-repellent fluids with a low surface tension. The interest of the medical world in silicone has grown exponentially since the 1940 s. $^{2}$ In some ways, silicone has an excellent biocompatibility profile: it is permanent, noncarcinogenic, minimally antigenic, and would not seem to favor bacterial growth. It can be easily sterilized and is able to maintain its state as the temperature changes. If silicone has found fertile ground in breast reconstruction with prostheses, the same cannot be said as a liquid filler. After more than 50 years, liquid silicone, unlike its solid and gel forms, is no longer used as a filling filler almost all over the world. Depending on the country, its use is forbidden or off-label. However, clinical experience has shown how the different silicone formulations, depending on the inoculation site, have different side effects. Classical minor complications including edema, erythema, skin texture change, and granulomas are reported with a frequency between 1 and $2 \%{ }^{3}$ Other complications, including recurrent cellulitis, ulcerations, migration, and nodule formation, have also been reported with silicone injections. ${ }^{3}$

Silicone migration or embolization as a result of large-volume injections and sometimes breast implant rupture are considered the worst complication, which do not allow encapsulation of the material. The migration of silicone can reach the lungs with a picture of parenchymal siliconosis. ${ }^{4,5}$ This complication can occur both in acute form with embolic modality and acute respiratory distress syndrome, ${ }^{5,6}$ or chronically. ${ }^{7}$ Respiratory symptoms are

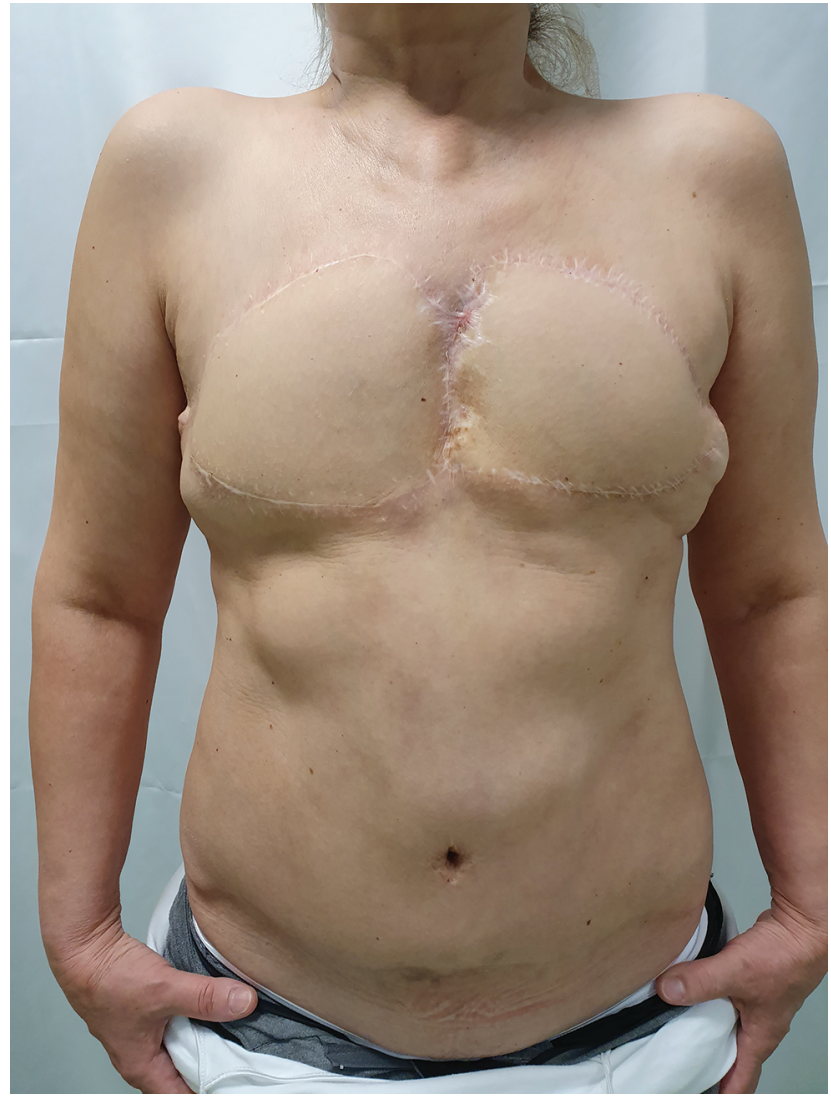

Fig. 6 Postoperative picture showing the patient after 3 months from the operation.

present within 72 hours after injection of higher dose silicone, but a delayed reaction is normally described up to a year and a half after injection. ${ }^{5}$ In this scenario, the release of silicone emboli leads to occlusion of the microvasculature and triggers the inflammatory response, resulting in pulmonary edema, hemorrhage, and subsequent fibrosis. Diagnosis of pneumonitis due to silicone liquid injection can be challenging due to a lack of an available specific algorithm and more diagnostic procedures are usually 
needed to confirm the diagnosis. First of all, silicone pneumonitis must be always suspected when a clinical history of silicone implant or injection is present. The radiological pattern includes subpleural infiltrates and peripherally distributed ground-glass opacities, and tissues biopsy shows histopathological features of alveolar hemorrhage and nonrefractile vacuole-like structure within the alveoli. ${ }^{8-10}$ Alternatively, the presence of alveolar macrophages with intracytoplasmic silicone inclusions in bronchoalveolar lavage sample is useful in facilitating a diagnosis. ${ }^{11}$

The case presented here represents a possible scenario of a complex of tissue and lung siliconosis after liquid silicone improper use. Despite the importance of medical support therapy, in this case, the contribution of the plastic surgeon has been crucial to improve the mechanism of thoracic expansion. We performed an accurate debridement and asportation of the scarring tissue and granulomas. For the reconstruction, we chose the deep inferior epigastric perforator flap. This flap is a good source of soft tissue, with a similar skin texture compared with the thoracic one. The donor site scar can be placed in an aesthetically acceptable location and could contribute to improve resultant abdominal contouring. Another advantage of this kind of flap is the possibility of double team working without changing patient's position. Before the procedure, in accordance with the patient and the anesthesiologist, we decided not to perform an aesthetic breast reconstruction. This choice was made to reduce the amount of tissue needed and to avoid longer operative times in a patient with such a severe reduction in pulmonary compliance. We planned a subsequent expander positioning, once the local and pulmonary situation were stable. We performed a postoperative spirometry exam, which did not observe a significant improvement in pulmonary volumes despite the patient being referred for a clinical reduction in respiratory and thoracic impairment. This curious clinicallaboratory dissociation might be attributed to the role played by the soft tissue scarring on thoracic expansion. We suppose that despite not influencing pulmonary volumes, breast scarring mechanically impaired lungs expansion. Its removal has probably contributed to eliminate one of the factors of the restrictive syndrome and the feeling of thoracic constriction perceived by the patient.

\section{Conclusion}

There is no consensus on the treatment of the silicone-induced pneumonitis. Surgical asportation of the silicone and scarring tissues is considered as high risk of adverse effects and technically complex. However, after a collegial discussion with the pulmonologist expertise, surgical debridement of the scarring tissue and reconstruction of the affected area could sometimes help to improve the ventilatory mechanism.

\section{Declaration of Competing Interest None.}

\section{Funding}

This research did not receive any specific grant from funding agencies in the public, commercial, or not-for-profit sectors.

\section{Conflict of Interest}

None declared.

\section{Acknowledgments \\ None.}

\section{References}

1 Thomas N R. Frederic Stanley Kipping-Pioneer in Silicon Chemistry: His Life \& Legacy. Silicon 2010;2:187-193

2 Frisch EE, Technology of silicones in biomedical applications. In Rubin L, ed. Biomaterials in Reconstructive Surgery. St. Louis: Mosby; 1983:73-90

3 Narins RS, Beer K. Liquid injectable silicone: a review of its history, immunology, technical considerations, complications, and potential. Plast Reconstr Surg 2006;118(3, Suppl):77S-84S

4 Gleeson JP, Redmond HP, O'Reilly S. Siliconosis and the long-term implications of silent breast implant rupture. Breast J 2019;25(5):1002-1003

$5 \mathrm{Ng} \mathrm{BH}$, Mat WR, Abeed NN, Hamid MFA, Yu-Lin AB, Soo CI. Silicone pneumonitis after gluteal filler: a case report and literature review. Respirol Case Rep 2020;8(3):e00538

6 Soeroso NN, Rhinsilva E, Soeroso L. Acute pneumonitis following breast silicone liquid injection. Respirol Case Rep 2018;6(6):e00335

7 Ryu AJ, Glazebrook KN, Samreen N, Bauer PR, Yi ES, Ryu JH. Spectrum of chronic complications related to silicone leakage and migration. Am J Med 2018;131(11):1383-1386

8 Restrepo CS, Artunduaga M, Carrillo JA, et al. Silicone pulmonary embolism: report of 10 cases and review of the literature. J Comput Assist Tomogr 2009;33(2):233-237

9 Price EA, Schueler H, Perper JA. Massive systemic silicone embolism: a case report and review of literature. Am J Forensic Med Pathol 2006;27(2):97-102

10 Chung KY, Kim SH, Kwon IH, et al. Clinicopathologic review of pulmonary silicone embolism with special emphasis on the resultant histologic diversity in the lung-a review of five cases. Yonsei Med J 2002;43(2):152-159

11 Chastre J, Basset F, Viau F, et al. Acute pneumonitis after subcutaneous injections of silicone in transsexual men. $\mathrm{N}$ Engl J Med 1983;308(13):764-767 